\title{
Risk Ratios and Special Education: The Cure Is Worse than the Disability
}

\author{
David C. Coker ${ }^{1, *}$ \\ ${ }^{1}$ Advanced Education Program, Fort Hays State University, Hays, KS, USA \\ *Correspondence: Advanced Education Program, Fort Hays State University, Hays, KS, USA. E-mail: \\ dccoker@fhsu.edu
}

Received: June 15, 2020

Accepted: July 6, $2020 \quad$ Online Published: July 21, 2020

doi:10.5430/wje.v10n4p1

URL: https://doi.org/10.5430/wje.v10n4p1

\begin{abstract}
Many researchers report risk ratios of White students to Black students with disabilities to show disproportionality and draw the conclusion discrimination exists. Risk ratios, upon further inspection, have methodological and philosophical problems which challenge the usefulness. A qualitative literature review provides a framework for understanding disproportionality and the use of risk ratios. Four themes underpin disproportionality findings, and a theory for future action was derived from the literature review. Recommendations to improve special education services are presented: universal screening, a standardized process, fidelity and research, and a focus on academic achievement.
\end{abstract}

Keywords: special education, over/underrepresentation, risk ratios, defining and diagnosing disabilities, equity

\section{Introduction}

Want to greatly decrease a student's chance of graduating? Want to decrease, permanently, a student's chance to learn and be successful after high school? What if the cure was worse than the disability? Many researchers unwittingly make the claim the only action worse than being identified with a disability is being placed in special education, stating there are too many students in special education who do not belong.

Farkas, Morgan, Hillemeier, Mitchell, and Woods (2020) computed risk ratios for special education placement as a factor of a district's academic achievement gap compared White students. The results suggested possibly an underrepresentation of Blacks in districts with either no gap or a low achievement gap, and as the gap increased, so did the special education representation. The authors state overrepresentation at the extreme levels, based off the adjusted risk ratios, might be ripe for investigation for systemic bias. How this research is new or useful remains to be seen, as researchers have long found such disparities exist nationally but possibly not regionally (Artiles \& Trent, 1994; Dunn, 1968; Ferri \& Connor, 2005; Manni, 1980; Morgan et al., 2017; Morgan et al., 1997).

Sullivan (2014) summed up the dilemma as "ongoing disproportionality strongly indicates systemic problems of inequity, prejudice, and marginalization within the education system" (p. 318). There is one central problem with the a priori assumption of the whole nature of using risk ratios as a basis of discrimination. Is special education so negative and harmful the very nature of offering individualized education plans as a free and appropriate public education is worse than no special education? A qualitative literature review examines if misdiagnoses and student achievement factor into reviews of racial disproportionality in special education. Recommendations follow the discussion of the continuing problem of the goal of special education.

\section{Methods}

The following section states the methodology used to conduct a qualitative literature review. The model is described, and then the sample and data analysis components detail the process. After the results, the interpretation is discussed, along with limitations. 


\subsection{Model}

The qualitative literature review used a constant comparison model to review disproportionality findings. Glaser (1965) stated constant comparison allows joint coding and analysis to develop theory. Four steps were utilized to operationalize the constant comparison method: selection of the data material, developing the aim, selecting questions to ask, and the results (Boeije, 2002). Three levels of coding and review, as recommended by Saldaña (2015), were used. There were two levels of introspection of the qualitative literature review: representation and legitimation (Onwuegbuzie, Leech, \& Collins, 2012).

Data were limited to either a meta-analysis, a review of literature, or large-scale studies concerning racial disproportionality for Black and White students in special education. The abstract, discussion, and conclusion were used in the comparison of the different studies to identify major themes. Microsoft Excel, Microsoft Word, and Wordclouds.com were used to conduct the qualitative analysis.

The aim of the study was to ascertain how disproportionality studies impact Black students within and out of special education. To develop representation, the following questions guided the review: Why does disproportionality matter? What impact does disproportionality have on students? What are the causes and effects? As the study progressed, other questions were added. Coding methods, to be used simultaneously, were in vivo, descriptive, focused, axial, and process. Finally, to develop legitimation, the results were checked during and after by memoing and synthesizing to reflect on the dilemma and future of disproportionality.

\subsection{Data Collection}

To conduct a qualitative literature review, articles from 2016-2020 were selected which reviewed racial disproportionality studies in special education for Black and White students. The goal was to select five to ten articles, which researchers such as Creswell and others state are sufficient to develop meaningful and comprehensive interpretations (Onwuegbuzie, Frels, \& Hwang, 2016). Google Scholar, EBSCO, and ERIC were searched to find articles. The following key words were used either individually or in different combinations to select articles: risk ratios, disproportionality, special education, meta-analysis, review, integrative synthesis, racial, minority, representation, overrepresentation, and underrepresentation.

Table 1. Literature Review Articles

\begin{tabular}{|c|c|c|c|}
\hline Authors & Year & Title & Method \\
\hline $\begin{array}{l}\text { Farkas, G., \& Morgan, } \\
\text { P. L. }\end{array}$ & 2018 & $\begin{array}{l}\text { Risk and race in measuring special } \\
\text { education need. Contexts, } 17(4), 72-74 \text {. }\end{array}$ & Qualitative review \\
\hline Cooc, N., \& Kiru, E. W. & 2018 & $\begin{array}{l}\text { Disproportionality in special education: } \\
\text { A synthesis of international research and } \\
\text { trends. The Journal of Special } \\
\text { Education, 52(3), 163-173. }\end{array}$ & Qualitative review \\
\hline $\begin{array}{l}\text { Grindal, T., Schifter, L. } \\
\text { A., Schwartz, G., \& } \\
\text { Hehir, T. }\end{array}$ & 2019 & $\begin{array}{l}\text { Racial differences in special education } \\
\text { identification and placement: Evidence } \\
\text { across three states. Harvard Educational } \\
\text { Review, } 89(4), 525-553 \text {. }\end{array}$ & $\begin{array}{l}\text { Quantitative analysis } \\
\text { by multiple variables }\end{array}$ \\
\hline $\begin{array}{l}\text { Kincaid, A. P., \& } \\
\text { Sullivan, A. L. }\end{array}$ & 2017 & $\begin{array}{l}\text { Parsing the relations of race and } \\
\text { socioeconomic status in special } \\
\text { education disproportionality. Remedial } \\
\text { and Special Education, } 38(3), 159-170 .\end{array}$ & $\begin{array}{l}\text { Quantitative analysis } \\
\text { using hierarchical } \\
\text { modeling }\end{array}$ \\
\hline $\begin{array}{l}\text { Morgan, P. L., Farkas, } \\
\text { G., Cook, M., Strassfeld, } \\
\text { N. M., Hillemeier, M. } \\
\text { M., Pun, W. H., \& }\end{array}$ & 2017 & $\begin{array}{l}\text { Are Black children disproportionately } \\
\text { overrepresented in special education? A } \\
\text { best-evidence synthesis. Exceptional } \\
\text { Children, 83(2), 181-198. }\end{array}$ & $\begin{array}{l}\text { Quantitative study } \\
\text { using regression }\end{array}$ \\
\hline
\end{tabular}


Once a suitable article was located, there was a check to ensure the article was relevant, peer reviewed, and synthesized findings of Black and White disproportionality in special education. Articles which dealt with other special education findings were not used. Furthermore, articles which did not include review or synthesis of multiple studies or were not large scale were not included. The abstract, discussion, and conclusion of each article were reviewed for codes, memos, and development of themes.

\subsection{Sample}

After conducting a search, five articles were located which were included. All articles met the parameters established: published since 2016, pertained to either a review or large-scale studies, and were published in peer reviewed journals. The articles are listed in Table 1.

\subsection{Data Analysis}

The review of the literature followed a constant comparison model using Microsoft Excel, Microsoft Word, and Wordcloud.com. After coding and memoing, there was a concurrent pass to develop relationships through comparing and contrasting. A third stage assembled all the relevant codes into categories, and conclusions were made. All conclusions were checked with the original documents for support, and additional clarifications were developed. Four key themes stood out. Two major themes were the problematic nature of research and systemic bias as causation. The two minor themes were school quality and student characteristics.

Research in disproportionality and risk ratios can be unified under one central tenet: Disproportionality as a construct lacks agreement and parameters which preclude a common, universal understanding. The question of what factors have the greatest impact cannot be definitively answered, and some claim there is disproportionality as underrepresentation, disproportionality needs qualified by academic achievement gap, and socioeconomic status (SES) might explain representation in special education. There is no one formula, and samples differ as much as the variables which might confound disproportionality. Models cannot accurately predict what will happen, and there are calls to overcome insufficiency in current practices to avoid what can be labeled "spurious estimates."

There is ubiquitous agreement "systematic" and "systemic bias" exist at the "structural level." Culturally biased and discriminatory practices are stated to be rampant and a major causation of disproportionality. The problem starts with the referral process and the subjective nature of disabilities which results in the "misattribution," "misidentification," and misdiagnosis of Black students. There "may" be "implicit bias" causing the system to fail to give "access" and proper placement to minority students.

The final two themes have much less support and lack consensus: school quality and student characteristics. There is research which says the school quality might matter, such as schools with high minority populations or an academic achievement gap. No depth of the issues is presented. Concerning characteristics of students, there is little focus except SES and parents' educational achievement might matter. Cultural barriers are stated as a possible reason for disproportionality.

\subsection{Interpretation}

Glaser (1965) and Saldaña (2015) stated a goal of qualitative research is to develop a theory which explains the phenomena under study while remaining faithful to the data, yet the theory can improve practices. There is disproportionality in some locations, though research fails to adequately explain why. The theory derived is systematic changes, centered around understanding cumulative deficits both within the individual and between groups, need to recenter the research and mission of special education predicated on optimizing students' academic outcomes. Four major components give a framework to understand disproportionality: the research paradigm, the mission and vision of disproportionality, move from untested surface change to second order change, and cumulative deficits. Before understanding the framework of the proposed theory, the background of the problem of disproportionality must first be addressed.

Disproportionality studies are rooted in the unequal, discriminatory treatment of Blacks in the past and the present. There is a concern the past of segregation might still be at play. Concern rests on misdiagnosing and incorrectly placing students in an education which is substandard and produces educational failure. Entire systems fail students, and radical improvements must happen to ensure all students receive a free and appropriate public education.

The research paradigm generally assumes disproportionality must exist and is a negative for Black students. Untested assumptions dominate the field. For disproportionality to be true, there must be no objective intake process, special education placements are worse than regular education, and the end results, besides changing a statistic, never become clear. To produce these findings, there is the assumption variance, also known as diversity, cannot exist in 
such a manner. There is no one definition of disproportionality because prevalence rates within and between groups cannot be modeled without considering extraneous variables which are localized.

With over 50 years since disproportionality became an issue in education, researchers seem no closer than when the issue started. There is a belief which drives disproportionality studies: Special education is substandard education. The research did not explicitly seek to find optimal academic placements for all students, but disproportionality does have the best interest of students as a goal by assuming misidentification is suboptimal. Ironically, the literature review revealed academic achievement of students affected by disproportionality is hardly mentioned. The goal seems to be numbers, not people. The lack of focus on the purpose of school indicates there is a loss of mission.

Mission loss is endemic to disproportionality study. There are questions never asked which should drive risk ratios and disproportionality studies, or the pursuit of equitable education for everyone. Why is special education as a practice harmful for students misidentified? What is the cost-benefit analysis? Do end results matter? If so, for whom? What kind of profession wrongs students in the entire process, from referral to services? There is a concerted lack of interest in academic achievement both within and outside of special education. Studies of disproportionality suggest many fixes and prescriptions, but one will see the recommendations are mostly untested surface policies with little thought about implementation or the ramifications.

Untested surface policies show little depth and often fall victim to jargon. There is no disaggregation of the system portrayed as monolithic and dysfunctional. Even when there is no disproportionality or Whites are overrepresented, there is no account for how the results are systemic bias. Systemic bias defies explanation in disproportionality studies, and who and what are the drivers need definition, research, and improvement. A finding in many studies was segregation might be an aim, but using loaded language with a negative historical connotation and lacking evidence of motives might distort the issue. Researchers in disproportionality appear to throw around the term systemic bias with little evidence to support the claim.

Massive incompetence drives the systemic bias, according to the studies. Otherwise, how could entire teams and processes from across the nation under multiple standards and requirements fail to carry out core functions of special education in a logical, capable fashion? If the system cannot diagnose and place Black students appropriately, then there would be little basis to believe White students receive a competent, appropriate evaluation and services. Billions of dollars and over a half century of research and practice are questionable. Future studies need to move from surface change to operationalize alleged systemic bias grounded in evidence.

Cultural competency and interpersonal communication are two frequently cited remedies for what ails risk ratios and disproportionality studies. Cultural competency and interpersonal communication do not appear as research-based practices to improve learning. Breaking down interpersonal communication to the denotational level, there is a level of absurdity to believe if teachers were more competent in talking, listening, and being empathetic, there would be less disproportionality. Like the cultural competency argument, which is a proxy for race, teachers are portrayed as negative in transactional communication, and students have no agency to either respond or adapt to a diverse world. Yet, one study found parental educational levels negatively correlated to disproportionality, suggesting the issue of agency is ripe for further discussion. Disproportionality studies need to shift to either research-based practices or forge new practices which are data driven.

Lastly, there is the policy of legal intervention by the Federal government to ensure the right rate in all places. The right rate and how to calculate the model remain elusive, which makes this policy unsustainable. Why not replicate what schools with the right rate practice? How can one assume students are accurately diagnosed at the macrolevel and microlevel? Which students with higher disproportionality need removed from special education, and how would students be removed? Why some students benefit from special education services and others do not remains illusory, and researchers need to check if an It's a Wonderful Life effect exists: Would students misidentified, according to risk ratios, be worse off if never identified? There should be a shift to disaggregating the system to find practices which serve all populations.

To serve all students, practices must examine the existence of cumulative deficits and respond at the individual level. Most disproportionality studies look at only groups, overlooking adverse childhood effects, poverty, and crime, etc., which vary by individual, school, and community. The other downside of overlooking cumulative deficits is students and parents are portrayed as pawns in the system, with no agency or self-determination. Parents must sign agreement of special education placement, yet disproportionality studies leave no room for the individual factor being anything other than discrimination and harmful. Black parents, like all parents, have real issues and concerns, and there is a problem to portray Black parents as powerless and uninformed. 
In other studies of education, cumulative effects have an onion model, where there are layers of harm from which are cause for concern. The individual effects need to be heard and accepted. The duality of systemic bias and adverse variables must be reconciled. Otherwise, one would assume special education teachers traffic in bad referrals, picking students by race and are lacking underlying issues which qualify for the support of special education. Students referred to special education have real issues and concerns, and changing a percentage to decrease qualification for special education services because there are the dangers of small classrooms, accommodations and modifications, individualized plans, extra safeguards, and ancillary services is counterintuitive.

Notwithstanding problems and criticisms, risk ratios and disproportionality studies seek to improve the lives of all students. There is a concern schools do not serve all students adequately and appropriately. Agreement does not exist on different models or causes, but there is agreement on the need to seek to identify and eliminate discrimination and racial biases. The qualitative review raises more questions than answered.

There is a theory which can combine all parts of the framework and most all educational research: All education research must optimize results of the end user. The research paradigm must identify the context which produces disproportionality, as the characteristics of students, parents, schools, and the community impact results. Disproportionality studies must shift to maximizing learning outcomes of all students, and current research does not spell how precluding students from all the services and protections of special education, in the face of failure, optimizes student learning and future outcomes.

\subsection{Limitations}

Legitimation means the qualitative research adequately reflects the original data by assessing convergence and corroboration of the evidence (Onwuegbuzie et al., 2016). All findings were checked for accuracy, and codes were drawn back to the sources. Consistency in themes and codes adds to the validity, and there was saturation of codes from the articles, indicating accuracy and agreement (Patton, 1999; Walsh \& Downe, 2005). Alexander (2020) points out all qualitative literature reviews are inherently personal and include the beliefs and views of the author. There were five studies from a limited time period, and there is the possibility other researchers would see different problems and concerns.

\section{Discussion}

The qualitative literature review raises substantive questions of the nature of risk ratios and disproportionality. Disproportionality is discussed first, and then the problem of the process of diagnosis is explored. There is an exploration of the need to focus on student outcomes, and policy recommendations are presented.

\subsection{Disproportionality}

Russo and Talbert-Johnson (1997) stated acceptable rates of Black students in special education. All the disproportionality findings operate on the spurious notion one normal distribution for every sample exists. Yet, one does not hold such beliefs in other fields about prevalence being equal in all settings. Juvenile detention centers long have reported histories of overrepresentation in special education (Coker, 2019). Outside of special education, males are systematically imprisoned at greater rates. In 2017, there were 111,360 females and 1,378,003 males incarcerated, which is 12.37 times as many males as females (Bronson \& Carson, 2019). Decades of research show Blacks have higher blood pressure and concomitant risks much higher than Whites or Hispanics (Douglas et al., 2003; Flack et al., 2010; James, Hartnett, \& Kalsbeek, 1983; Nguyen-Huynh, Young, Alexeeff, Hatfield, \& Sidney, 2019; Teteh, Lee, Montgomery, \& Wilson, 2017).

Special education disabilities are ill-defined and can result from bias (Artiles, Kozleski, Trent, Osher, \& Ortiz, 2010). At a philosophical level, if there intergroup and intragroup differences did not exist, then there would neither be diversity nor the need for differentiation. What separates other fields, such as imprisonment and blood pressure, is no one makes the claim crime victims systematically identify males because of an implicit anti-female bias or sphygmomanometers have different ways of understanding the millimeters of mercury depending on the arm's color. Special education lacks such rigor and objectivity, but that also does not mean the only result is bias.

What research says every school, which have individually small samples, cannot be anything other than Gaussian? Are wealthy districts the same as districts with high poverty and related health problems? Depending on the researcher, there can be overrepresentation and underrepresentation at the same time. Farkas (2004) claimed inequity in achievements exist starting from preschool and was rooted in parenting practices. Other researchers also found some disabilities, such as emotional and behavioral issues, were systematically underidentified (Kauffman, Mock, \& Simpson, 2007). There is no research which says small samples and large samples must have the same distribution, 
and real-world research shows clusters of problems in all fields of study.

Two other issues are at stake: evaluation of white students and the lack of evidence to draw a conclusion. Presumably, there must be Type I and II errors in the diagnoses of white students with disabilities; if the misdiagnosis rate was equal to black students, then there would still be the conundrum of overrepresentation. The conclusion could be drawn then the misdiagnosis rate, according to researchers of risk ratios, might be even more inflated and might need either a correction factor or normalization. Nevertheless, no one points to an evaluation in these schools which is not an honest attempt to answer extreme problems of failure by students. If many evaluations are wrong as alleged by risk ratios not following the White prevalence rate, then there is nothing reliable and valid about the diagnostic process. Why the white rate is the benchmark and the acceptable standard also remains unverified and unsupported. A half century of research produced no usable results.

A moral hazard exists, which needs researched and was also a factor in the qualitative literature review. Treating students like numbers might lead to de facto quotas (Zamora-Duran \& Artiles, 1997; Zhang \& Katsiyannis, 2002). Numbers, not needs, might drive the system in place of student need (Gordon, 2017). Imagine if doctors had to meet the same inane equal ratios. After the exact ratio of Blacks and Whites were identified as having high blood pressure, the most prudent activity would be to no longer diagnose for fear of being labeled prejudiced. When one decides every classroom in every school must have the same students, one will force schools to game the system to mirror rates dictated by distant bureaucrats over students' needs. Equal proportionality would be worse than disproportionality and could serve as a proxy for underrepresentation as a possibility in many locales.

Research in disproportionality suffers from comparisons of different samples, methodologies, and definitions at all stages of investigation, including referral, assessment, and placement (Cruz \& Rodl, 2018). Personally, I have read hundreds of IEPs from many jurisdictions which have unbelievably low expectations: Everyone passes, even the student sleeping or absent; the lowest grade a student can get is a $70 \%$; disruptive behavior results in a timeout or cool down period which can last the majority of the school day with no one ever mentioning what about the missed instructional time. All the students still receive praise nine or ten times as much as criticism. How could a student not be confused with such positive feedback and no consequences? A guiding question for researchers could be: Would one want one's child in such a program?

\subsection{Diagnosis of Disabilities}

There is an assumption of the disproportionality studies concerning school psychology: At the aggregate level, there must be subjectivity and imprecision in the validity and reliability in disability identification and diagnosis to render results meaningless. Some failures are worse than others. There are at least three concerns: normal distribution assumptions, individual-level research, and lack of objective diagnostic procedures.

One does not read how, at the individual level, there was any malfeasance. Presumably, there is the possibility Simpson's paradox is real (Kievit, Frankenhuis, Waldorp, \& Borsboom, 2013): Some draw the conclusions of systemic bias using studies looking at groups of students (Waitoller, Artiles, \& Cheney, 2010), but no study was located which demonstrated bias at the individual level. More importantly, if special education identification and diagnosis used reliable and valid systems, then one would easily replicate the process used on individual students.

As the system exists now, there can only be the conclusion schools systematically assess and evaluate students in a manner which is haphazard, riddled with error, and lacks replicability. There should be more historiography like the Annales school to ferret out the individual voices to give agency to the ratios preordained by researchers. There would be shocking findings.

Even as assessment data improved and showed increases in developmental delays (Zablotsky et al., 2019), not one study was found which showed students were placed in special education solely due to race, though there were many inferences and implications. Students in special education rarely are the valedictorian with an ACT of 36 and best boy or girl citizen, let alone on grade level. Students are real people with real problems, felt by parents and educators. Students placed in special education generally have lengthy histories of failure, often affecting other teachers and students through disruptive behavior and an inability and, or refusal to complete work. In the end, parents signed off. The possibility of group differences moderated and mediated by numerous factors, such as socioeconomic status, neonatal drug use, and adverse childhood effects, etc. (Cooc \& Kiru, 2018; Harry \& Fenton, 2016; Kincaid \& Sullivan, 2017), could render many risk ratios untenable at the individual and small group level.

Diagnoses are highly subjective and often do not include research-based interventions (Voulgarides, Zwerger, \& Noguera, 2013). Confirmation bias might explain diagnoses of school psychologists (O'Reilly, Northcraft, \& Sabers, 1989), with school psychologists found to disregard evidence in place of concerns by teachers and other stakeholders 
(Sullivan, Sadeh, \& Houri, 2019). A central underpinning of overrepresentation is there is no inherent scientific basis for disability identification.

School psychology, to researchers who look at overrepresentation, does not exist as a coherent field with consistent application and results. If disproportionality is true, the level of Type I errors in some schools would approach 50\% or greater, and if one factored in Type II errors, one concludes the significance of findings are arbitrary and capricious. There are few other explanations how teachers, social workers, and school psychologists from all parts of the country, backgrounds, and many universities cannot develop a rational, replicable diagnosis.

\subsection{Questions of Outcome}

Possibly disproportionality of minorities is reducing, as evidenced by one study (Zhang, Katsiyannis, Ju, \& Roberts, 2014). Researchers do not state how teachers, special education teachers, social workers, school psychologists, parents, administrators, and school boards conspire to rig the system against students who do not have a disability. Either way, in or out, schools must let a student fail in regular education or fail in special education. Besides being a bean counter, the ratio counters offer no solution to improve the lives of students. There is no cause and effect, but one conclusion held by the disproportionality researcher is certain: Placing students in special education is detrimental to a student's long-term chances of success even though persistent failure already exists. Failure outside of special education is preferable to failure in special education.

Hanushek, Kain, and Rivkin (1998) make the claim special education raises academic achievement. Studies, such as Hurwitz, Perry, Cohen, and Skiba (2020), are problematic because one cannot infer growth was because of special education. The better way to prove this assertion would be to run an experiment where students diagnosed with a disability and qualifying for special education services would be placed in an experimental group receiving services and a similarly matched cohort would be placed in a control sample where the students did not receive services. Barring such an unethical study, proxies, such as test scores comparing students with and without disabilities will have to be used. The results are not promising.

There is an implicit assumption the compensatory, individualized special education placement is harmful and to be avoided in favor of the current placement which produces failure. There is the belief special education placement is a negative with low expectations (Liou \& Rotheram-Fuller, 2019; Rosenbaum, Kulieke, \& Rubinowitz, 1987; Voltz \& Fore, 2006), else why would there be concern if mass misdiagnoses resulted in individualized plans, replete with small classes, extra assistance, and teams of support. If special education produced an individualized plan which bridged the gap between regular education and a student's individual needs, one would presume every student would benefit from special education placement. The conclusion is the risk ratio of overrepresentation many researchers report is a proxy for the risk ratio of misdiagnosis and future failure by special education placement.

The idea of compensatory education sounds promising. Kounin (1970) long ago spoke about a teacher having withitness or knowing and anticipating what problems or issues exist within the classroom. Many syntheses of disproportionality studies recommend culturally responsive teaching. A prescription to reduce disproportionality is culturally responsive pedagogy, yet there is little research on the efficacy of what can only be termed an unproven approach (Bottiani, Larson, Debnam, Bischoff, \& Bradshaw, 2018). Special education is replete with fads or poor practices.

Learned helplessness has been known for decades to develop in students with disabilities, with lower student engagement and lower student achievement (Filippello, Buzzai, Costa, Orecchio, \& Sorrenti, 2020; Hoy, 1986; Thomas, 1979; Weisz, 1979). There are policies today which state students with disabilities cannot be retained, cannot be suspended or expelled, and must be babysat by teachers no matter what. Within the cycle of special education, many students quickly realize there are no expectations for anything. Compensatory education evolved into a place where students can be held away from the general population.

What prevents a student with a learning disability from having the same behavioral expectations as a student without disabilities? Encouraging extreme behavior with no real consequences predictably results in a downward spiral of behavior and academic achievement. No college professor or adult would create a setting where little is expected. Common practices often do not mirror findings which have been utilized for decades. Hattie (2012) recounted the surprise many teachers had when told direct instruction was often superior to discovery learning, groupings, and other popular methods. Many teachers overuse praise and work to build students' self-esteem, though research does not support such practices (Baumeister, Campbell, Krueger, \& Vohs, 2003).

Many teachers are extreme enablers, disconnected, unhelpful, and chaotic, with few to no expectation students will ever have to do anything independently (Stronge, Ward, Tucker, \& Hindman, 2007; Walls, Nardi, von Minden, \& 
Hoffman, 2002). By precluding failure at any costs, these same teachers spiral behavioral and academic expectations until there are no meaningful standards. Teachers have been observed where the teachers do everything, including for high school students, reading directions, defining every word, and doing every problem with a student. The system requires this enabling, as a teacher who made a student achieve like the teacher had to in when the teacher was a student would face discipline and dismissal.

Many schools operate off the belief students with disabilities cannot be disciplined, allowing abject lawlessness to stymy the individual's learning and create disruptions which prevent entire classes from learning. In my practice with students across many jurisdictions and speaking with special education teachers, there are many students who speak about the lack of any meaningful standards in behavior and academic work. Perhaps special education needs a Hippocratic oath: First, do not harm.

The no suspension idea practiced in many schools sounds like a meaningful reform, but no one says what to do about the 17-year-old who reads at a $3^{\text {rd }}$ grade level, has little interest in learning, and is regularly disruptive to the point other students cannot learn. The no retention idea means students know there is a disassociation between effort and achievement, and the students who work are quickly disillusioned. Worse yet, the student placed in special education can practice increasingly worse behavior, with no repercussions. All students receive the same promotion and diploma.

George Orwell has it right: All failures are equal, but some failures are more equal than others. In the long run, districts which stick to the non-special education failure in favor of doing nothing will save money. Hosp \& Reschly (2003) reviewed the history of disproportionality and stated stigmatization and ineffective education were concerns. Risk ratios serve to do the opposite of the intended effect of improved outcomes: Enforce a substandard education, as there are no research findings improved risk ratios produced any improved academic achievement at the individual, school, or district level. The long-term outcomes of students never factor into the equation. What a way to enforce the status quo.

Kauffman (1999) made many recommendations, which were based on the premise special education had robust, useful research. Other researchers questioned if special education resulted in harmful outcomes (Meyer \& Patton, 2001). Pogrow (1996) pointed out there was a problem with reformers, who often advocated for the researcher's own pet programs and theories. Current practices will have to change. Practices are often unscientific, which do not focus on outcomes and have replicability problems (Kauffman, Anastasiou, \& Maag, 2017; Makel et al., 2016).

Research and findings do not impact teachers in the way intended (Artiles et al., 2010). If college professors had to practice the theories peddled in academia, the theories would change. There are students who are not held accountable behaviorally or academically. What could go wrong? Common sense and what worked for centuries have been jettisoned for practices which are unacceptable in any adult setting. There are students who neither work nor do what is expected, and there is eventually a sad comeuppance once students find college and work do not operate off such whims.

Pogrow (2017) stated research suffers from confirmation bias of research and often becomes unusable. Findings need to replicable after an effect size is found, but published research itself suffers from a bias of being much more likely to publish if the effect sizes are skewed (Chow \& Ekholm, 2018). Research translation remains elusive, and even John Hattie's massive tome Visible Learning remains more mysticism than reality. Education is not the only field struggling with poor research and translation, as medicine and psychology suffer from similar problems (Benjamin et al., 2018). Research needs disseminated, monitored, and reported in a systematic fashion. There are thousands of papers about best practices over the past one hundred years, but NAEP results (and ratios) show there is a disconnect between what researchers claim need done, what teachers do, and what works.

\subsection{Policy Recommendations}

In place of ratios and the debate over whether a small high school should be the same as every other school in the nation, there must be a shift in special education policy around four axes: universal screening, a standardized process, fidelity and research, and a focus on academic achievement. Much of the research and practices already exist, but there will be a shift from novel practices and fads which show either little promise or harm education. The lack of focus on outcomes must change.

The Nation's Report Card (2017a, 2017b) makes clear why the unstated assumption of the cure being worse than the disability exists. For $4^{\text {th }}$ graders in 2017 , the risk ratio of students with disabilities (SWD) compared to students without disabilities for reading at the proficiency level or higher is 0.31 (12\% SWD to $39 \%$ without disabilities) and math is 0.36 ( $16 \%$ SWD to $44 \%$ without disabilities). The risk of meeting standards once placed in special education 
is not very promising.

Universal screening has the potential to recast the debate about disproportionality around accurate diagnosis rates (Dever, Raines, Dowdy, \& Hostutler, 2016). Students are screened for lead poisoning. There are requirements for physicals for students to enter school, at $6^{\text {th }}$ grade, and $9^{\text {th }}$ grade. There are, at minimum, yearly dental screenings. The brain does not get the same level of attention, and neither does the social, emotional, and academic abilities of students. Student maturation, injury, and ecological variables impact a student from year to year. Screenings should be a part of the regular check-up for students. By using screening methods, the entire debate flips from solely looking for deficits and reacting to a proactive approach.

The ability to accurately diagnose students should not vary by zip code, district, or state. Special education as a field needs to be standardized, replicable methods to screen, assess and evaluate, and diagnose students suspected of having a disability. If there was a standardized method of disability identification, then the idea a normal distribution must be the same everywhere could properly be quantified and qualified. More importantly, there is a lack of quality research which can be translated into positive practices which improve learning outcomes (Hedges, 2018; Kaestle, 1993; Sroufe, 1997). Regardless of where one stands on the efficacy of special education programming, current practices show special education is substandard education.

Disabilities need to be reimagined. Learning disabilities (LD) and seriously emotionally disturbed (SED) are so vague to be meaningless. Such a conclusion is nothing new, as researchers have claimed for decades diagnoses and disabilities are vague (Frey, 2019; Hallahan, Keller, \& Ball, 1986; Thomas, 1979). No one says plegia. There must be specificity beyond the generic. For the shift to happen, though, the screening and evaluation process must identify a construct which is a real disability beyond waiting for students to fail (Cartledge, Kea, Watson, \& Oif, 2016). The current system often fits diagnosis decisions into the existing problem of students failing to respond to interventions which might or might not be rigorous, relevant, and implemented with fidelity.

Student achievement-based outcomes must become the focus to replace dubious ratios. Sullivan and Proctor (2016) call for a nuanced view of diagnosis and placement based on the benefit or harm imposed. Not all people with mental and health problems need interventions, and the same could be true for special education. How there is harm for an individualized plan tailored to the needs of a student is never spelled out. Special education spends billions annually and assigns staff members to create small classes to help every student reach their potential. Yet, as Farkas et al. (2020) make clear, there should be an investigation if too many students receive small classes, extra assistance, and increased parent communication.

Disproportionality can result in the Office of Civil Rights (OCR) suing (Robinson \& Norton, 2019) to ensure the national rate applies to all small and large samples. District will be forced to revise disability rates by ignoring blacks who are failing. Revenue will be shunted away for the OCR defense, weakening an already poor education. In the end, the present failure will not be replaced with a failure replete with counseling, individualized panning, specialized training, and small classrooms.

Researchers teaching and presenting need to become practitioners to demonstrate success of the latest findings and admonitions. Few negative findings are published, calling into question the validity of many studies which only find positive, novel effects in a sensational manner (Bloom, 2017; Ioannidis, 2019). Many of the claims of researchers are not effective in practice, and there is little effort to bridge the gap between research and implementation (Boser \& McDaniels, 2018). When effort does not equal achievement and lawlessness reigns supreme, students in special education suffer. Presenters advocating for no suspension, restorative justice, and quotas need to have participants refuse to work and be disruptive in their own classes and see how researchers make the system work. The result is low expectations in behavior and academic achievement.

Universal screening, standardized diagnoses, and refining research practices must stay focused on improving student achievement. The assumptions of the dangers of special education are well founded, but regular education often fares no better. Considering the opposite of new practices could transform the system, especially the historical practices which were replaced with untested assumptions. Optimizing the end user experience connects the framework to moving disproportionality to examine the results of policies at the individual level.

\section{Conclusion}

While other researchers have questioned the complexity of special education to be reduced to simple measures of over or underrepresentation (Gordon, 2017; Skiba, Artiles, Kozleski, Losen, \& Harry, 2016), the present investigation suggests the wrong questions are being asked. There is a lack of concern for academic achievement for 
students as the goal of examining and rectifying risk ratios and disproportionality for Black students. A uniform screening and diagnosis process could be a gatekeeper for all students, and research must work with and through practitioners to focus on academic achievement.

Risk ratios and disproportionality need reframed around a workable research paradigm and meaningful policy changes. To be effective, systematic change must honor the mission and values of special education. By moving research and practice to optimizing the end user's outcome, change at the individual and group level can become the objective of educational research. Instead of the one study and publication, translation and replication could push the boundaries of a field which has unrealized potential.

\section{References}

Alexander, P. A. (2020). Methodological guidance paper: The art and science of quality systematic reviews. Review of Educational Research, 90(1), 6-23. https://doi.org/10.3102/0034654319854352

Artiles, A. J., \& Trent, S. C. (1994). Overrepresentation of minority students in special education: A continuing debate. The Journal of Special Education, 27(4), 410-437. https://doi.org/10.1177/002246699402700404

Artiles, A. J., Kozleski, E. B., Trent, S. C., Osher, D., \& Ortiz, A. (2010). Justifying and explaining disproportionality, 1968-2008: A critique of underlying views of culture. Exceptional Children, 76(3), 279-299. https://doi.org/10.1177\%2F001440291007600303

Baumeister, R. F., Campbell, J. D., Krueger, J. I., \& Vohs, K. D. (2003). Does high self-esteem cause better performance, interpersonal success, happiness, or healthier lifestyles? Psychological Science in the Public Interest, 4(1), 1-44. https://doi.org/10.1111/1529-1006.01431

Benjamin, D. J., Berger, J. O., Johannesson, M., Nosek, B. A., Wagenmakers, E. J., Berk, R., ... \& Cesarini, D. (2018). Redefine statistical significance. Nature Human Behaviour, 2(1), 6. https://doi.org/10.1038/s41562-017-0189-z

Bloom, P. (2017). Against empathy: The case for rational compassion. Random House.

Boeije, H. (2002). A purposeful approach to the constant comparative method in the analysis of qualitative interviews. Quality and Quantity, 36(4), 391-409. https://doi.org/10.1023/a:1020909529486

Boser, U., \& McDaniels, A. (2018). Addressing the gap between education research and practice. Center for American Progress. Retrieved from https://www.americanprogress.org/issues/education-k-12/reports/

Bottiani, J. H., Larson, K. E., Debnam, K. J., Bischoff, C. M., \& Bradshaw, C. P. (2018). Promoting educators' use of culturally responsive practices: A systematic review of inservice interventions. Journal of Teacher Education, 69(4), 367-385. https://doi.org/10.1177\%2F0022487117722553

Bronson, J., \& Carson, E. A. (2019). Prisoners in 2017. US Department of Justice, Office of Justice Programs. Retrieved from https://www.bjs.gov/content/pub/pdf/p17.pdf

Cartledge, G., Kea, C. D., Watson, M., \& Oif, A. (2016). Special education disproportionality: A review of response to intervention and culturally relevant pedagogy. Multiple Voices for Ethnically Diverse Exceptional Learners, 16(1), 29-49. https://doi.org/10.5555/2158-396X.16.1.29

Chow, J. C., \& Ekholm, E. (2018). Do published studies yield larger effect sizes than unpublished studies in education and special education? A meta-review. Education Psychology Review, 30, 727-744. https://doi.org/10.1007/s10648-018-9437-7

Coker, D. C. (2019). Multiple regression analysis of noncognitive factors affecting academic achievement of juvenile delinquents [Unpublished doctoral dissertation]. American College of Education.

Cooc, N., \& Kiru, E. W. (2018). Disproportionality in special education: A synthesis of international research and trends. The Journal of Special Education, 52(3), 163-173. https://doi.org/10.1177/0022466918772300

Cruz, R. A., \& Rodl, J. E. (2018). An integrative synthesis of literature on disproportionality in special education. The Journal of Special Education, 52(1), 50-63. https://doi.org/10.1177/0022466918758707

Dever, B. V., Raines, T. C., Dowdy, E., \& Hostutler, C. (2016). Addressing disproportionality in special education using a universal screening approach. The Journal of Negro Education, 85(1), 59-71. https://doi.org/10.7709/jnegroeducation.85.1.0059

Douglas, J. G., Bakris, G. L., Epstein, M., Ferdinand, K. C., Ferrario, C., Flack, J. M., ... \& Ofili, E. O. (2003). 
Management of high blood pressure in African Americans: consensus statement of the Hypertension in African Americans Working Group of the International Society on Hypertension in Blacks. Archives of Internal Medicine, 163(5), 525-541. https://doi.org/10.1001/archinte.163.5.525

Dunn, L. M. (1968). Special education for the mildly retarded-is much of it justifiable? Exceptional Children, 35(1), 5-22. https://doi.org/10.1177/001440296803500101

Farkas, G. (2004). The black-white test score gap. Contexts, 3(2), 12-19. https://doi.org/10.1525\%2Fctx.2004.3.2.12

Farkas, G., \& Morgan, P. L. (2018). Risk and race in measuring special education need. Contexts, 17(4), $72-74$. https://doi.org/10.1177/1536504218812876

Farkas, G., Morgan, P. L., Hillemeier, M. M., Mitchell, C., \& Woods, A. D. (2020). District-level achievement gaps explain Black and Hispanic overrepresentation in special education. Exceptional Children, 86(4), 374-392. https://doi.org/10.1177\%2F0014402919893695

Ferri, B. A., \& Connor, D. J. (2005). In the shadow of Brown: Special education and overrepresentation of students of color. Remedial and Special education, 26(2), 93-100. https://doi.org/10.1177/07419325050260020401

Filippello, P., Buzzai, C., Costa, S., Orecchio, S., \& Sorrenti, L. (2020). Teaching style and academic achievement: The mediating role of learned helplessness and mastery orientation. Psychology in the Schools, 57(1), 5-16. https://doi.org/10.1002/pits.22315

Flack, J. M., Sica, D. A., Bakris, G., Brown, A. L., Ferdinand, K. C., Grimm, R. H., Jr., ... \& Nasser, S. (2010). Management of high blood pressure in Blacks: an update of the International Society on Hypertension in Blacks $\begin{array}{llll}\text { Consensus } & \text { Statement. } & \text { Hypertension, } & \text { 786-800. }\end{array}$ https://doi.org/10.1161/HYPERTENSIONAHA.110.152892

Frey, J. R. (2019). Assessment for special education: Diagnosis and placement. The Annals of the American Academy of Political and Social Science, 683(1), 149-161. https://doi.org/10.1177\%2F0002716219841352

Glaser, B. G. (1965). The constant comparative method of qualitative analysis. Social Problems, 12(4), 436-445. https://doi.org/10.2307/798843

Gordon, N. (2017, September 20). Race, poverty, and interpreting overrepresentation in special education. Washington, DC: Brookings Institution. Retrieved from https://www.brookings.edu/

Grindal, T., Schifter, L. A., Schwartz, G., \& Hehir, T. (2019). Racial differences in special education identification and placement: Evidence across three states. Harvard Educational Review, 89(4), 525-553. https://doi.org/10.17763/1943-5045-89.4.525

Hallahan, D. P., Keller, C. E., \& Ball, D. W. (1986). A comparison of prevalence rate variability from state to state for each of the categories of special education. Remedial and Special Education, 7(2), 8-14. https://doi.org/10.1177/074193258600700204

Hanushek, E. A., Kain, J. F., \& Rivkin, S. G. (1998). Does special education raise academic achievement for students with disabilities? (No. w6690). National Bureau of Economic Research. https://doi.org/10.3386/w6690

Harry, B., \& Fenton, P. (2016). Risk in schooling: The contribution of qualitative research to our understanding of the overrepresentation of minorities in special education. Multiple Voices for Ethnically Diverse Exceptional Learners, 16(1), 17-28. https://doi.org/10.4324/9780203770979-13

Hattie, J. (2012). Visible learning for teachers: Maximizing impact on learning. Routledge.

Hedges, L. V. (2018). Challenges in building usable knowledge in education. Journal of Research on Educational Effectiveness, 11(1), 1-21. https://doi.org/10.1080/19345747.2017.1375583

Hosp, J. L., \& Reschly, D. J. (2003). Referral rates for intervention or assessment: A meta-analysis of racial differences. The Journal of Special Education, 37(2), 67-80. https://doi.org/10.1177/00224669030370020201

Hoy, C. (1986). Preventing learned helplessness. Academic Therapy, 22(1), 11-18. https://doi.org/10.1177/105345128602200102

Hurwitz, S., Perry, B., Cohen, E. D., \& Skiba, R. (2020). Special education and individualized academic growth: A longitudinal assessment of outcomes for students with disabilities. American Educational Research Journal, 57(2), 576-611. https://doi.org/10.3102/0002831219857054

Ioannidis, J. P. (2019). Why most published research findings are false. Chance, 32(1), 4-13. 
https://doi.org/10.1080/09332480.2019.1579573

James, S. A., Hartnett, S. A., \& Kalsbeek, W. D. (1983). John Henryism and blood pressure differences among black men. Journal of Behavioral Medicine, 6(3), 259-278. https://doi.org/10.1007/bf01315113

Kaestle, C. (1993). The awful reputation of education research. Educational Researcher, 22(1), 23-31. https://doi.org/10.2307/1177303

Kauffman, J. M. (1999). Commentary: Today's special education and its messages for tomorrow. The Journal of Special Education, 32(4), 244-254. https://doi.org/10.1177\%2F002246699903200405

Kauffman, J. M., Anastasiou, D., \& Maag, J. W. (2017). Special education at the crossroad: An identity crisis and the need for a scientific reconstruction. Exceptionality, 25(2), 139-155. https://doi.org/10.1080/09362835.2016.1238380

Kauffman, J., Mock, D., \& Simpson, R. (2007). Problems related to underservice of students with emotional or behavioral disorders. Behavioral Disorders, 33(1), 43-57. https://doi.org/10.1177/019874290703300104

Kievit, R., Frankenhuis, W. E., Waldorp, L., \& Borsboom, D. (2013). Simpson's paradox in psychological science: a practical guide. Frontiers in Psychology, 4, 513. https://doi.org/10.3389/fpsyg.2013.00513

Kincaid, A. P., \& Sullivan, A. L. (2017). Parsing the relations of race and socioeconomic status in special education $\begin{array}{lllll}\text { disproportionality. Remedial and Special } & \text { Education, }\end{array}$ https://doi.org/10.1177/0741932516671199

Kounin, J. S. (1970). Discipline and group management in classrooms. Holt, Rinehart \& Winston.

Liou, D. D., \& Rotheram-Fuller, E. (2019). Where is the real reform? African American students and their school's expectations for academic performance. Urban Education, 54(3), 397-429. https://doi.org/10.1177\%2F0042085915623340

Makel, M. C., Plucker, J. A., Freeman, J., Lombardi, A., Simonsen, B., \& Coyne, M. (2016). Replication of special education research: Necessary but far too rare. Remedial and Special Education, 37(4), 205-212. https://doi.org/10.1177\%2F0741932516646083

Manni, J. L. (1980). The status of minority group representation in special education programs in the state of New Jersey: A summary report (Report by the New Jersey State Department of Education). Trenton, NJ: Bureau of Pupil Personnel Services.

Meyer, G., \& Patton, J. M. (2001). On the nexus of race, disability, and overrepresentation: What do we know? Where do we go? IDEAs that work. Washington, DC: National Institute for Urban School Improvement, Office of Special Education Programs (OSEP). Retrieved from https://files.eric.ed.gov/fulltext/ED462487.pdf

Morgan, P. L., Farkas, G., Cook, M., Strassfeld, N. M., Hillemeier, M. M., Pun, W. H., \& Schussler, D. L. (2017). Are Black children disproportionately overrepresented in special education? A best-evidence synthesis. Exceptional Children, 83(2), 181-198. https://doi.org/10.1177\%2F0014402916664042

Morgan, P. L., Woods, A. D., Wang, Y., Hillemeier, M. M., Farkas, G., \& Mitchell, C. (2020). Are schools in the US South using special education to segregate students by race? Exceptional Children, 86(3), 255-275. https://doi.org/10.1177\%2F0014402919868486

Nguyen-Huynh, M. N., Young, J. D., Alexeeff, S., Hatfield, M. K., \& Sidney, S. (2019). Shake Rattle \& Roll-Design and rationale for a pragmatic trial to improve blood pressure control among blacks with persistent hypertension. Contemporary Clinical Trials, 76, 85-92. https://doi.org/10.1016/j.cct.2018.11.012

Onwuegbuzie, A. J., Frels, R. K., \& Hwang, E. (2016). Mapping Saldaña's coding methods onto the literature review process. Journal of Educational Issues, 2(1), 130-150. https://doi.org/10.5296/jei.v2i1.8931

Onwuegbuzie, A. J., Leech, N. L., \& Collins, K. M. (2012). Qualitative analysis techniques for the review of the literature. Qualitative Report, 17, 56. Retrieved from https://nsuworks.nova.edu/tqr/

O'Reilly, C., Northcraft, G. B., \& Sabers, D. (1989). The confirmation bias in special education eligibility decisions. School Psychology Review, 18(1), 126-135. https://doi.org/10.1080/02796015.1989.12085406

Patton, M. Q. (1999). Enhancing the quality and credibility of qualitative analysis. Health Services Research, 34(5 Pt 2), 1189-1208.

Pogrow, S. (1996). Reforming the wannabe reformers. Phi Delta Kappan, 77(10), 656. 
Pogrow, S. (2017). The failure of the US education research establishment to identify effective practices: Beware "effective practices policies." Education Policy Analysis Archives, 25(5), n5. https://doi.org/10.14507/epaa.25.2517

Robinson, G. C., \& Norton, P. C. (2019). A decade of disproportionality: A state-level analysis of African American students enrolled in the primary disability category of speech or language impairment. Language, Speech, and Hearing Services in Schools, 50(2), 267-282. https://doi.org/10.1044/2018_lshss-17-0149

Rosenbaum, J. E., Kulieke, M. J., \& Rubinowitz, L. S. (1987). Low-income black children in white suburban schools: A study of school and student responses. The Journal of Negro Education, 56(1), 35-43. https://doi.org/10.2307/2295381

Russo, C. J., \& Talbert-Johnson, C. (1997). The overrepresentation of African American children in special education: The resegregation of educational programming? Education and Urban Society, 29(2), 136-148. https://doi.org/10.1177/0013124597029002002

Saldaña, J. (2015). The coding manual for qualitative researchers. Sage.

Skiba, R. J., Artiles, A. J., Kozleski, E. B., Losen, D. J., \& Harry, E. G. (2016). Risks and consequences of oversimplifying educational inequities: A response to Morgan et al. (2015). Educational Researcher, 45(3), 221-225. https://doi.org/10.3102/0013189x16644606

Sroufe, G. E. (1997). Research news and Comment: Improving the "awful reputation" of education research. Educational Researcher, 26(7), 26-28. https://doi.org/10.3102/0013189X026007026

Stronge, J. H., Ward, T. J., Tucker, P. D., \& Hindman, J. L. (2007). What is the relationship between teacher quality and student achievement? An exploratory study. Journal of Personnel Evaluation in Education, 20(3-4), 165-184. https://doi.org/10.1007/s11092-008-9053-z

Sullivan, A. L., \& Proctor, S. L. (2016, September). The shield or the sword? Revisiting the debate on racial disproportionality in special education and implications for school psychologists. In School Psychology Forum, 10(3). Retrieved from https://nasponline.org/

Sullivan, A. L., Sadeh, S., \& Houri, A. K. (2019). Are school psychologists' special education eligibility decisions reliable and unbiased?: A multi-study experimental investigation. Journal of School Psychology, 77, 90-109. https://doi.org/10.1016/j.jsp.2019.10.006

Teteh, D. K., Lee, J. W., Montgomery, S. B., \& Wilson, C. M. (2017). Validity of self-reported high blood pressure among black and white seventh-day Adventists. International Journal of Health Sciences and Research, 7(7), 212-220.

The Nation's Report Card. (2017a). NAEP Report Card: Mathematics. Retrieved from https://www.nationsreportcard.gov/math_2017/nation/achievement?grade=4

The Nation's Report Card. (2017b). NAEP Report Card: Reading. Retrieved from https://www.nationsreportcard.gov/reading/nation/achievement?grade $=4$

Thomas, A. (1979). Learned helplessness and expectancy factors: Implications for research in learning disabilities. Review of Educational Research, 49(2), 208-221. https://doi.org/10.3102/00346543049002208

Voltz, D. L., \& Fore, C., III. (2006). Urban special education in the context of standards-based reform. Remedial and Special Education, 27(6), 329-336. https://doi.org/10.1177/07419325060270060201

Voulgarides, C. K., Zwerger, N., \& Noguera, P. (2013). Identifying the root causes of disproportionality. New York, NY: Metropolitan Center for Research on Equity and the Transformation of Schools.

Waitoller, F. R., Artiles, A. J., \& Cheney, D. A. (2010). The miner's canary: A review of overrepresentation research and explanations. The Journal of Special Education, 44(1), 29-49. https://doi.org/10.1177/0022466908329226

Walls, R. T., Nardi, A. H., Minden, A. M., \& Hoffman, N. (2002). The characteristics of effective and ineffective teachers. Teacher Education Quarterly, 29(1), 39-48.

Walsh, D., \& Downe, S. (2005). Meta-synthesis method for qualitative research: A literature review. Journal of Advanced Nursing, 50(2), 204-211. https://doi.org/10.1111/j.1365-2648.2005.03380.x

Weisz, J. R. (1979). Perceived control and learned helplessness among retarded and nonretarded children: A developmental analysis. Developmental Psychology, 15(3), 311. https://doi.org/10.1037/0012-1649.15.3.311 
Zablotsky, B., Black, L. I., Maenner, M. J., Schieve, L. A., Danielson, M. L., Bitsko, R. H., ... \& Boyle, C. A. (2019). Prevalence and trends of developmental disabilities among children in the United States: 2009-2017. Pediatrics, 144(4), e20190811. https://doi.org/10.1542/peds.2019-0811

Zamora-Duran, G., \& Artiles, A. J. (1997). Disproportionate representation: Current issues and future directions. In A. J. Artiles \& G. Zamora-Duran (Eds.), Reducing disproportionate representation of culturally diverse students in special and gifted education (pp. 87-93). Council for Exceptional Children.

Zhang, D., \& Katsiyannis, A. (2002). Minority representation in special education: A persistent challenge. Remedial and Special Education, 23(3), 180-187. https://doi.org/10.1177\%2F07419325020230030601

Zhang, D., Katsiyannis, A., Ju, S., \& Roberts, E. (2014). Minority representation in special education: 5-year trends. Journal of Child and Family Studies, 23(1), 118-127. https://doi.org/10.1007/s10826-012-9698-6

\section{Copyrights}

Copyright for this article is retained by the author(s), with first publication rights granted to the journal.

This is an open-access article distributed under the terms and conditions of the Creative Commons Attribution license (http://creativecommons.org/licenses/by/4.0/). 